\begin{tabular}{l} 
US TECHNOLOGY TRENDS 1990-94 \\
Comparisons with Japan and Europe \\
Energy \\
Energy efficiency \\
Storage, distribution, and transmission \\
Improved generation \\
\hline Environmental quality \\
Monitoring and assessment \\
Pollution control \\
Remediation and restoration \\
Information and communication \\
Components \\
Communications \\
Computing systems \\
Information management \\
Intelligent complex adaptive systems* \\
Sensors \\
Software and toolkits \\
Living systems \\
Biotechnology \\
Medical technologies \\
Agriculture and food technologies \\
Human systems \\
Manufacturing \\
Discrete product manufacturing \\
Continous materials processing* \\
Micro/nanofabrication and machining \\
\hline Materials \\
Materials \\
Structures \\
Transportation \\
Aerodynamics \\
Avionics and controls \\
Propulsion and power \\
Systems integration \\
Human interface \\
US Technology position relative to: Japan \\
1990-94 Trend: Improved \\
* based on limited information \\
\hline
\end{tabular}

\title{
US lead falters in technology race
}

Washington. Although the United States remains on a par with or ahead of Europe and Japan in all strategically 'critical' technologies, its overall dominance is slipping, according to a report prepared by the Office of Science and Technology and submitted to President Bill Clinton last week.

The report was prepared in response to legislation passed by Congress in 1990 which calls for a report every two years up to 2000 , identifying critical technologies. The legislation specifies that the reviewing panel should be made up of industrialists, academics and government officials.

In the table above, which summarizes its main conclusions, the position of each symbol indicates where the US currently stands in comparison with either Japan or Europe, and the shape of the symbol indicates whether its position is going up or down.

In no area of critical technology does the report consider that the US lags behind its two main rivals. But it points out that having a technological lead does not necessarily mean that a country or region has the great- est market share in a particular field.

Compared with Europe, the panel found that US has a substantial lead only in the technology of the interface between humans and machines - for example, in long-duration spaceflight, or in the advanced computing of the so-called glass cockpit. In this area, the US is increasing its lead over both Europe and Japan.

In the overall comparison with Japan, the US leads in ten critical technologies, and is increasing its lead in four of these: human interface, human systems, information management, and software and tool-kits.

The main aims of the report are to identify areas that should be a focus of federal support in the future, to provide industry with a guide to potential areas of cooperative research and development, and to provide Congress with information that it can use to support policy decisions. But in the latter case - given the current scepticism of law-makers towards technological research programmes - the report may well fall on stony ground.
Helen Gavaghan

\section{New York researchers question claims of 'first' AIDS case}

Paris. The debate over the origins of human immunodeficiency virus (HIV) appears about to reopen dramatically following new research results questioning the identification of a man who died of pneumonia in the British city of Manchester in 1959 as the world's first case of AIDS.

The claim that tissues from David Carr, a former seaman, contained genes for HIV was made in The Lancet in 1990 by a group of researchers led by Gerald Corbitt, director of the virology unit at the University of Manchester's medical school. But these results are now being challenged by studies carried out by a group led by David Ho, director of the Aaron Diamond AIDS Research Center at the New York University School of Medicine.

Following a report of his findings published in The Independent newspaper last week, Ho confirmed in a statement with his colleague T. Zhu that, although their group had found HIV in DNA samples left over from the 1990 analysis by the Manchester researchers, the full sequence of the virus showed it to be indistinguishable from strains prevalent around 1990, "thereby rendering the interpretation of results difficult".

Moreover, while the sequence analysis also showed the virus to be identical to that isolated earlier by Corbitt's group, further PCR studies - this time using stored tissue samples taken from Carr's corpse - failed to detect any HIV, thus contradicting the first set of studies.

Further efforts to resolve the apparent discrepancy showed that the HLA tissue type from the second set of materials differed from those found in the initial samples. "These findings suggested that the two sets of clinical materials did not come from a single person," say Ho and Zhu.

The two researchers say they can offer "no explanation" for the contradictory findings, although The Independent speculates they could be explained by Corbitt's group having mistakenly used tissue from a different patient to Carr. But George Williams, the former pathologist at Manchester University who carried out the post-mortem on Carr, has described this as "impossible", adding that he is "absolutely confident of the authenticity of the material."

Another possibility, says the paper, is that someone deliberately switched the tissues. Manchester University has since launched an inquiry into the matter, and intends to repeat the experiments carried out by Ho's group. Ho and Zhu say that, as their data are prepared for publication, they "welcome an independent evaluation by another competent and objective laboratory".

Declan Butler 